\title{
Design of an Automatic Water Level Controller Using Mercury Float Switch
}

\author{
${ }^{1}$ Erua J. Band, ${ }^{2}$ Anyasi, F. I. \\ ${ }^{1,2}$ Department of Electrical and Electronics Engineering, AmbroseAlli University, P.M.B 14, Ekpoma, Edo \\ State, Nigeria.
}

\begin{abstract}
This paper presents the design of an automatic water level controller aimed at providing an appropriate control to pump water to an overhead thank when empty and automatically stop the pump when the tank is full. The system incorporates two mains contactor which are energized to provide a direct online start of the motor. An over load relay which senses the presence of excess current and disconnect the supply and a mercury flood switch which uses the Archimedes principle of floatation to provide the electrical contact to switch ON or OFF supply to the motor when the tank is empty or full respectively. This is capable of providing a seamless utilization of water at domestic and industrial level without causing spillage.

Key words: Automatic controller floatation, utilization, overload.
\end{abstract}

\section{Introduction}

Water is a universal solvent which plays an important role in our everyday life. Water is one of the most common substances found in nature. It is used in our everyday activities. Sources of water include rain water, river water, lake water and sea water etc. Rain water is the most accessible source of water in most localities, but in the last century pipe - borne water was invented. This water is free from germs but contains some mineral salts; it is generally accepted in most countries and is used as a source of drinking water (Harrington et al. 2010).

The world is experiencing water shortage, which implies that water source should be managed so as to minimize wastage. For instance, in Modernized Societies, almost every bathroom is equipped with water heater tanks and in most buildings there are overhead water tanks. In some homes, we will find out that the boreholes and wells have tanks for water storage before pumping up to the overhead tank. People generally switch on their water pump when their tanks are short of water i.e. when the taps stop running and switch off the water pump when the tanks start over flowing. This results in unnecessary wastage and sometimes unavailability of water in cases of emergency. To avoid wastage and any form of exposure to hazard that may result from overflow of water, the need for an automatic water pump arose, hence this design work (Choe et al. 1996).

At the household level, people switch on the water pumps and set off to work or even fall asleep, forgetting to switch off the mains when the tank or reservoir is full. This results to wastage and often flood. On some occasions, when the tank or reservoir is placed on top of the building, over time the weight of the tank can affect the building structure. It can also be a form of pollution to the environment and also a form of wastage especially in household where a borehole cannot be afforded. Thus the need for a constant and reliable water supply is important for our needs (Harrington 1989).

The average pumping machine is not in control of the amount of liquid or water it pumps. If the water is left running for over a long period of time without stoppage, it can constitute a form of hazard by flooding the area.

In addition, when a machine is left to run for a long time, its components tend to develop faults, the machine becomes inefficient and after sometime, it completely breaks down

There is an urgent need to incorporate an automatic controller with water level detector to check overflow and overrun of water pump machines.

The automatic water pump controller also finds its application in farms, industries, offices, households and all places that a water reservoir/tank is needed.

In view of the foregoing, due consideration was given in this work to the design and realization of a highly efficient automatic water pump control with level sensing and overload protection to cut-off supply to the pump in case of an overload or short circuit faults, see Figure 1. 


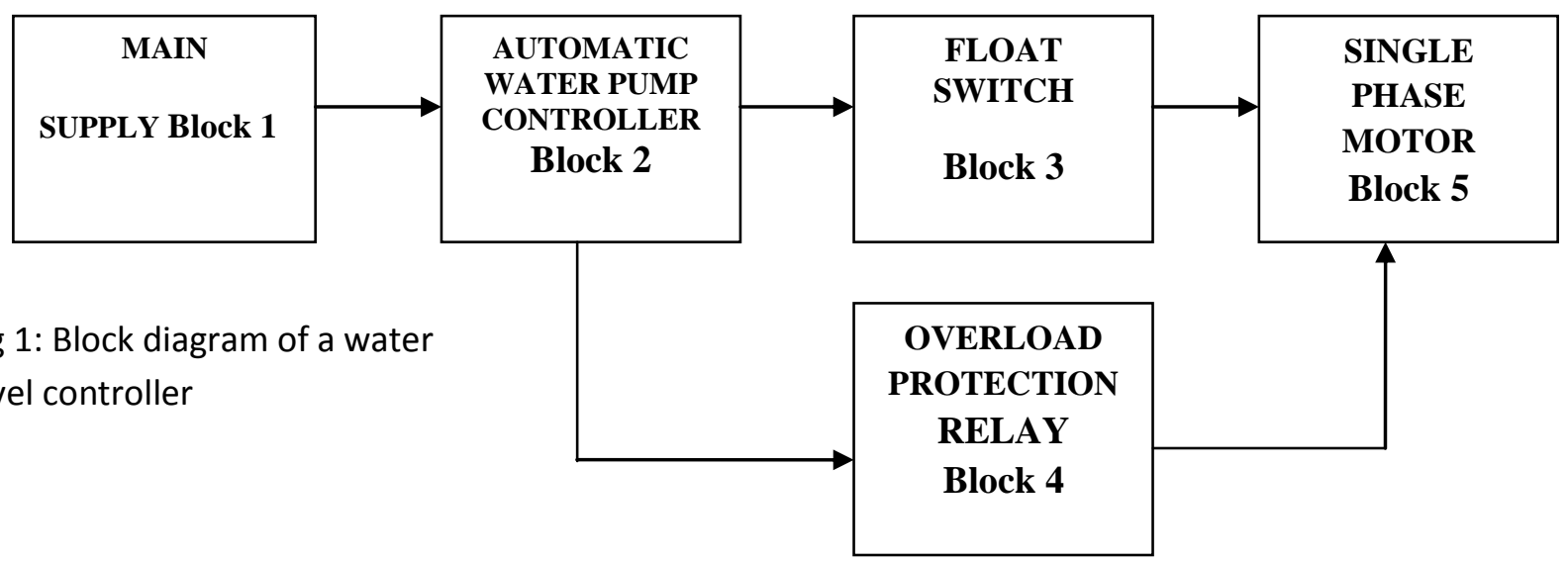

\section{DESIGN CRITERIAL}

The design of the automatic water pump controller system involved the calculation of component values and their specifications. The individual stages design and their operational principle. The design consisted of the following stages;

- Main Supply stage (Block 1)

- Automatic Water Pump controller Stage(Block 2)

- Mercury Float Switch(Block 3)

- Overload Protection Relay(Block 4)

- Single Phase Motor(Block 5)

The $240 \mathrm{~V}$ single phase mains supply is fed to the automatic water pump controller and the controller is connected to the flow switch and the single phase motor using a control circuit arrangement. The overload protection relay provides a feedback path between the controller and the motor, such that when excess current is supplied to the motor, the protection relay will sense it and cut-offpower to the motor.

The design includes components like Miniature Circuit Breaker, Contactors, which are wired in such a way that it enables the supply of power to both the float switch and the overload protection relay at same time. "Block 4" the overload protection relay, monitors the current being supplied to the motor and "Block 3" the float switch, monitors the water level in the water storage tank. The float switch actuates the single phase water pump motor which pumps water to the overhead tank.

\section{OVERLOAD PROTECTION RELAY}

Overload relays are designed to meet the special protective needs of motor control circuits.

- They allow harmless temporary overloads (such as the high current drawn at motor starting) without disrupting the circuit.

- They will trip and open a circuit if current is high enough to cause motor damage over a period of time.

- Can be reset once the overload is removed ( Jones 1993)

\section{Construction and function}

Thermal overload relays are 3 poles. The motor current flows through their bimetals ( 1 per phase) which are indirectly heated. Under the effect of the heating, the bimetals bend; causing the relay to trip and the position of the auxiliary contacts to change (Everest 2001).

The relay settingsrange is graduated in amps. In compliance with international and national standards, the setting current is the motor nominal current and not the tripping current (no tripping at $1.05 \mathrm{x}$ setting current, tripping at $1.2 \mathrm{x}$ setting current).

The relays are built to be self protecting.In the event of an overload the short circuit protection device is activated. Figure 2 shows the device and its component parts. 


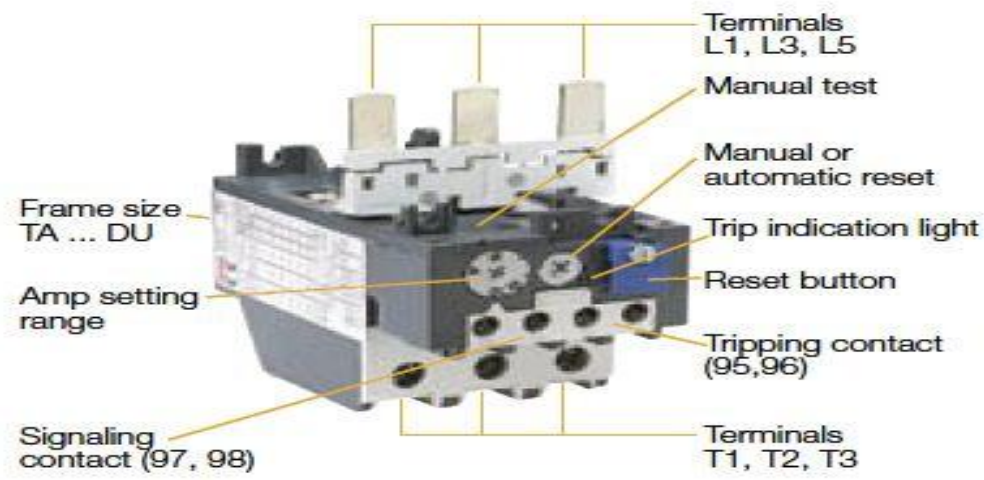

Fig2: A Thermal Overload Relay( www.circuitstoday.com)

\section{FLOAT SWITCH}

A float switch is a device used to detect the level of liquid within a tank. The switch may be used in a pump, an indicator, an alarm, or other devices.

Float switches range from small to large and may be as simple as a mercury switch inside a hinged float or as complex as a series of optical or conductance sensors producing discrete outputs as the liquid reaches many different levels within the tank. Perhaps the most common type of float switch is simply a float raising a rod that actuates a micro-switch. A very common application of this float is in the sump pumps and condensate pumps, where the switch detects the rising level of liquid in the sump or tank and energizes an electrical pump which then pumps the liquid out until that level of the liquid has been substantially reduced, at which the pump is switch off again. Float switches are often adjustable and can include substantial hysteresis i.e. the switch "turn on" point may be much higher than the "shut off" point. This minimizes the on - off cycling of the associated pump (Warren 2010).

\section{MERCURY FLOAT SWITCH}

A mercury switch (also known as a mercury tilt switch) is a switch whose purpose is to allow or interrupt the flow of electric current in an electrical circuit in a manner that is dependent on the switch's physical position or alignment relative to the direction of the "pull" of earth's gravity, or other inertia.

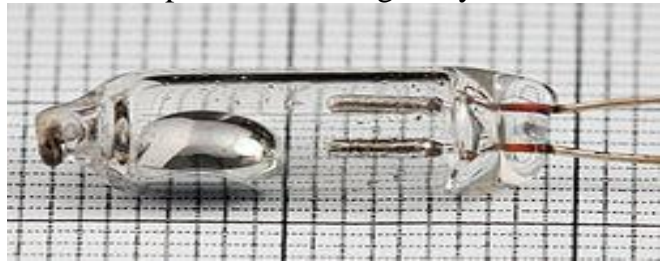

Fig 3: A Single-Pole, Single-Throw (SPST) mercury

Mercury switches consist of one or more sets of electrical contacts in a sealed glass envelope which contains a bead of mercury. The envelope may also contain air, an inert gas, or a vacuum. Gravity is constantly pulling the drop of mercury to the lowest point in the envelope. When the switch is tilted in the appropriate direction, the mercury touches a set of contacts, thus completing the electrical circuit through those contacts. Tilting the switch the opposite direction causes the mercury to move away from that set of contacts, thus breaking that circuit. The switch may contain multiple sets of contacts, closing different sets at different angles allowing, for example, Single-Pole, Double-Throw (SPDT) operation,see Figure 3.

Advantages of the mercury switch over other types are that the contacts are enclosed, so oxidation of the contact points is unlikely; in hazardous locations, interrupting the circuit will not emit a spark that can ignite flammable gasses. Contacts stay clean, and even if an internal arc is produced, the contact surfaces are renewed on every operation, so the contacts don't wear out. Even a small drop of mercury has a low resistance, so switches can carry useful amounts of current in a small size. The sensitivity of the drop to gravity provides a unique sensing function, and lends itself to simple, low-force mechanisms for manual or automatic operation. The switches are quiet as there are no contacts that abruptly snap together. The mass of the moving mercury drop can provide an "over center" effect to avoid chattering as the switch is tilted. Multiple contacts can be included in the envelope for two or more circuits.

A mercury float switch consists of a mercury tilt switch, a lever balance and 2 counter weights for the lever balance and a float ball, see Figure 4. 


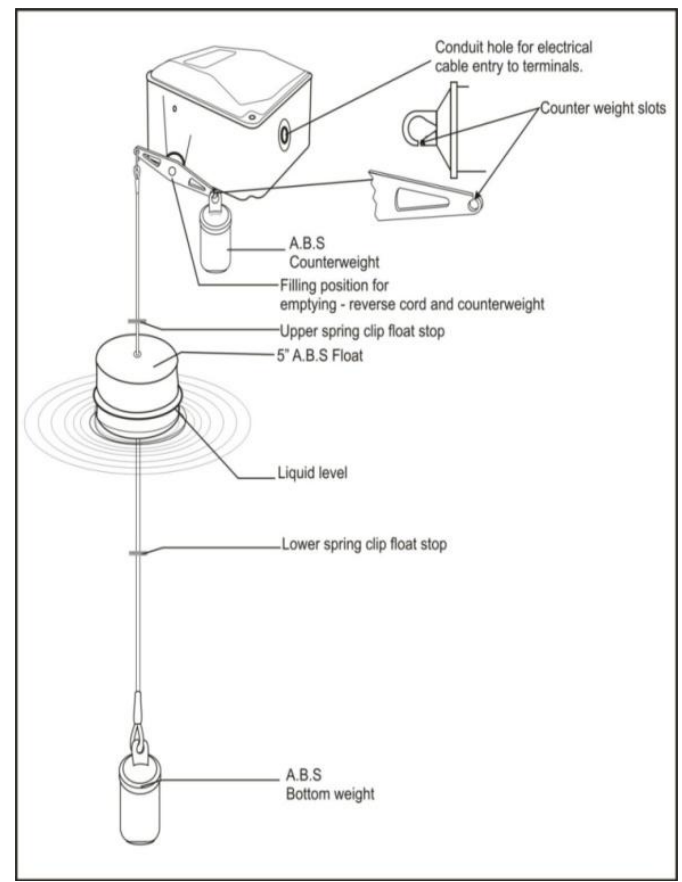

Fig 4: A Mercury Float Switch Diagram (www.amazon.com)

\section{CALCULATIONS AND CHOICE OF COMPONENTS}

\section{Design analysis}

Considering a borehole depth of $250 \mathrm{~m}$, a single phase, $1.5 \mathrm{~h} . \mathrm{p}$ (horse power) pump motor was chosen.This wasfound to besuitable for pumping water from such depth (the depth of a borehole is proportional to the horse power of the motor). The operating voltage of the motor is 240Va.c. The current capacity of the motor was calculated with the formula:

$$
\mathrm{P}=\mathrm{VI} \operatorname{Cos} \Phi
$$

Where $\quad \mathrm{P}=$ Power rating of the Induction motor $=1.5 \mathrm{~h} . \mathrm{p}=746 \mathrm{x} 1.5$ watts

$\mathrm{V}=$ Operating voltage $=240 \mathrm{v}$

$\mathrm{I}=$ Current rating

$\operatorname{Cos} \Phi=$ Power factor $=1 \simeq 0.8$

Calculating for I we obtained

$\mathrm{I}=5.82 \mathrm{~A} \sim 6 \mathrm{~A}$

The size of cable required to connect the motor to the power supply was chosen to be $4 \mathrm{~mm}^{2}$. This choice was based on the distance of 25 meters from the motor to the supply point and the voltage drop per ampere per meter from the IEE table of current carrying capacity and associated voltage drops (Theraja et al. 2002).

The circuit breaker was connected directly to the main a.c. source. The current rating of the circuit breaker was $1.45 \mathrm{x}$ the design current (current drawn by motor).

$\mathrm{I}_{\mathrm{cb}}=1.45 \times 6=8.7$

Therefore, preferred value of the circuit breaker was 10A.

Electromechanical contactor was used to switch ON and OFF the load from the supply. The load in this case was the pumping machine. This is because it is usually rated to handle starting and any transient Load current.

The choice of contactor was determine by the power rating of the motor since it is the contactor that will carry the load current to the motor(direct online starter). From previous calculation a current of approximately $6 \mathrm{~A}$ will flow through the terminals of the contactor when the motor is running. Consequently a three pole contactor of $16 \mathrm{~A}$ was chosen to allow for transient effect and temperature effect.

Motor nominal current $=6 \mathrm{Amps}$

No tripping current $=1.05 \times 6=6.3 \mathrm{Amps}$

Tripping current $=1.2 \times 6=7.2 \mathrm{Amps}$

Therefore, the thermal overload protection relay is set to 7 Amps. That means the overload protection relay will trip at any current value $\geq 7$ Amps.

Advantages of use of overload protection relay over fuse cannot be over emphasized due to the following reasons: 
- It responds quickly to fault.

- It provides means of indicating when the motor has tripped on overload fault.

- It can be reset when the fault current has been removed, unlike a fuse that has to be replaced.

- It's tripping current can be varied, thereby making it useful at different ratings unlike the fuse that can only be use for one specific rating which it was designed for.

\section{OPERATION OF AUTOMATIC WATER PUMP CONTROLLER}

The control unit is made up of 1 miniature circuit breaker, 2 contactors, 1overload protection relay, 2 indicating lamps, $1 \mathrm{OFF} / \mathrm{ON}$ switch and float switch.

Main supply, through the circuit breaker provides the power to energizethe first contactor. At the same instance, supply gets to the float switch, second contactor and the green lamp comes on, indicating there is power in the circuit.

If the supply from the second contactor is not up to the tripping current of 7Amps of the overload protection relay, supply gets to water pump motor, but if it exceeds $7 \mathrm{Amps}$, the overload protection relay trips. The automatic switching ON/OFF of the water pump motor depends on the level of water in the reservoir tank which is monitored by the mercury float switch (UN 2012)

At instance when the water level in the tank has dropped to a lower limit (empty), the float switch with two counter weights and a float ball attached to one side of the counter weight will now dangle to a side in order for mercury to flow and complete the switch on the circuit where there is more weight. The one that is heavier will be on one side (i.e. a counter weight and float ball). It works on Archimedes principle of floatation which states that"Any object, wholly or partially immersed in a fluid, is buoyed up by a force equal tothe weight of the fluid displaced by the object"

When the circuit is completed, the water pump motor is actuated. Therefore water is pumped into the reservoir tank. As the tank gets filled, the float ball begins to move upwards with the level of the water in the tank until an upper limit is reached. At this limit, the weight of the float ball and the counter weight at same side is displaced in the liquid, thereby causing the switch to dangle to the side of the single counter weight which becomes heavier than the side with a counter weight and float ball. At this point, the mercury flows to disconnect the switch and supply is cut-off from the motor (Obinabo et al. 2010).

\section{CONSTRUCTION OF A PROTO-TYPE}

A proto-type was constructed and tested and the pump was able to pump water to fill an overhead tank of 2000 liters in record time. The interior view of the constructed work is as shown in Figure 5.

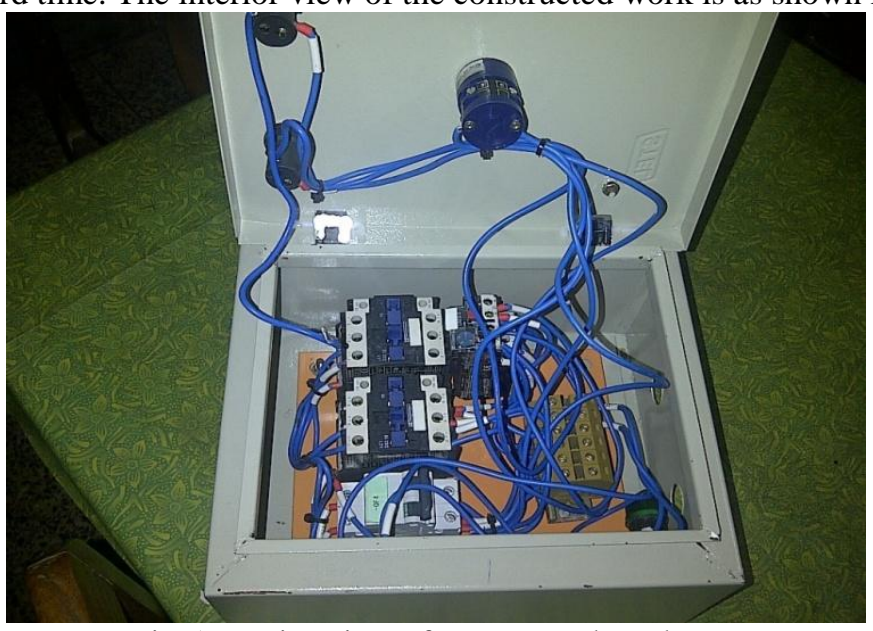

Fig.5:Interior view of constructed work

\section{Conclusion}

The aim of the design of an automatic control mechanism using float switch for a domestic water pump was successfully realized.

The system worked according to specification and proved quite satisfactory. It is relatively affordable, durable and efficient. Hence, give room for ease of operation and high level of reliability.The system would provide a clean and efficient way of using water for both domestic and industrial application thereby avoiding pollution from water spillage associated with the manual control of a water pump.

Finally, it reduces stress associated with manual water pump controller, which require that somebody go to physically switch them on and off. 
We recommend this device to private individuals Government and cooperate organization where there is a need for large consumption of water and the demand for a neat and hygienic environment free from water pollution.

\section{References}

[1]. Everest, D.B. "Mechanical and Electrical Services Prices Book”,E and F Spoon,London, $3{ }^{\text {rd }}$ Edition, $2001, P g$ 30 - 31.

[2]. Harrington J. “Automated Process Control Electronics”, Definer Publisher 1989.New York $1^{\text {st }}$ Edition pg $285-297$.

[3]. Jones, L."Electrical for Tomorrow's World”, Cambridge University Press, Cambridge, $2^{\text {nd }}$ Edition, 1993 , Pg 180 - 189,200 - 217.

[4]. Obinabo E.C. "Control System Theory" Bowens Nigeria Ltd, Warri; Delta State, Nigeria, $1^{\text {st }}$ Edition.2010Pg $260-261$.

[5]. Oroge C.O. "Control System Engineering” University PressLtd Ibadan $\quad 11^{\text {st }}$ Edition 1996 pp 67 - 69.

[6]. Theraja A.K “A Text Book of Electrical Engineering Technology”,S. Chandand Theraja, B.L and Company, New Delhi 21 Edition, 2002.Pg $1244-1248$.

[7]. Choe K.D, Whittington“The economic benefit of surface water quality improvements in and D. Laurin developing countries a study of Davao, Philippines" Land economy vol. 72 (4) 1996 pp 510-517.

[8]. Harring W, krupnick A. "Economic losses of water disease outbreak" Journal ofurban andspofford . W Economics Vol. 25(4) pp $110-127$

[9]. Water supply and sanitation collaborative council "The global sanitation fund progress report", UN 2012.

[10]. Warren Viessma "Water supply and pollution control”www.amazon.com 2010.

[11]. Automatic water level controller circuit www.mycircuittoday.com 2013.

[12]. UNICEF NEWS: Drinking water and sanitation, 2012 